\title{
TRAJETÓRIAS DE VIDAS DANÇANTES: A ELABORAÇÃO DA CORPOREIDADE DE PROFESSORES
}

\author{
DANCE LIVING PATHWAYS: THE PREPARATION OF TEACHER \\ CORPORATION
}

\section{VOIES DE VIE DE LA DANSE: LA PRÉPARATION DE LA SOCIÉTÉ DES ENSEIGNANTS}

\author{
Roberta Maria Zambon Maziero \\ Graduada em Educação Física - UNICEP \\ Mestre em Educação escolar - UNESP \\ Doutoranda em Educação - UFSCar \\ Email: roberta.maziero@gmail.com \\ Maristela Angotti \\ Graduada em Pedagogia - UNESP \\ Doutorado em Educação - UFSCar \\ Docente do Curso de Pedagogia FCL/UNESP/Araraquara \\ E-mail: maristela_angotti@hotmail.com
}

\section{RESUMO}

O presente artigo trata da elaboração da corporeidade de três professoras e um professor que possuem experiências com a dança em suas trajetórias de vida pessoal e profissional. Utiliza pressupostos da Fenomenologia, propondo um entrelaçamento dos conceitos de corporeidade, cultura, dança e formação de professores. Emprega uma abordagem qualitativa na coleta das narrativas, organizadas em três blocos de significação. As descrições revelam experiências com a dança na vida familiar, formação inicial, continuada e contínua em serviço, apontando aspectos da corporeidade ligados as vivências com esta manifestação cultural em diferentes âmbitos. A prática de uma dança mais performática na qual o corpo é tratado como objeto passa por transformações, durante os períodos de formação, com destaque para a formação contínua em serviço na possibilidade de reflexão e compreensão de suas trajetórias de vida marcadas pela dança como geradora de aprendizado de si e da realidade.

Palavras-chave: Dança. Corporeidade. Formação de professor(a)

\section{SUMMARY}

This article deals with the elaboration of the corporeity of three teachers and a teacher who have experiences with dance in their personal and professional life trajectories. It uses assumptions of the Phenomenology, proposing an interlacing of the concepts of corporeity, culture, dance and teacher training. It employs a qualitative approach in the collection of narratives, organized into three blocks of meaning. The descriptions reveal experiences with dance in family life, initial formation, continuous and continuous in service, pointing out aspects of the corporeity linked to the experiences with this cultural manifestation in different scopes. The practice of a more performative dance in which the body is treated as an object undergoes transformations during the formative periods, with emphasis on the continuous formation in service in the

61

RELEDUC | ISE | v. 2 | n. 1 | fev. 2019 
possibility of reflection and understanding of its life trajectories marked by dance as the generator of learning of self and reality.

Keywords: Dance. Corporeity. Teacher training

\section{RÉSUMÉ}

Cet article traite de l'élaboration de la corporéité de trois enseignants et d'un enseignant ayant une expérience de la danse dans leur parcours de vie personnel et professionnel. Il utilise des hypothèses de la phénoménologie, proposant un entrelacement des concepts de corporéité, de culture, de danse et de formation des enseignants. Il utilise une approche qualitative dans la collection de récits, organisée en trois blocs de sens. Les descriptions révèlent des expériences de danse dans la vie de famille, de formation initiale, de service continu et de service continu, soulignant les aspects de la corporéité liés aux expériences de cette manifestation culturelle à différents niveaux. La pratique d'une danse plus performative dans laquelle le corps est traité comme un objet subit des transformations au cours des périodes de formation, l'accent étant mis sur la formation continue au service dans la possibilité de réflexion et de compréhension de ses trajectoires de vie marquées par la danse en tant que générateur de apprentissage de soi et de la réalité.

Mots-clés: Danse. Corporeity. Formation des enseignants

\section{INTRODUÇÃO}

O presente $\operatorname{artigo~}^{1}$ trata da elaboração da corporeidade de professores de dança pelas experiências e reflexões vividas em trajetórias pessoais e profissionais. Desenvolve o estudo dos conceitos de corporeidade, cultura, dança e formação de professores em suas intersecções, visando desvelar a trama de significados apresentados aqui como ferramentas forjadas "nos atritos com o real, atravessados pela exigência própria da partilha (divisão, luta, vínculo) das experiências, narrações e das invenções com outros, em lugares de criações, de discussões e de ensino, universitários e artísticos” (BARDET, 2014, p.20).

Para tanto, elegemos os pressupostos da Fenomenologia tratados pela autora e autores: Chauí (1986); Merleau-Ponty (2013-2014); Paulo Freire (2015-2016); Rezende (1990); Garaudy (1980), além de outras(os) que desenvolvem seus estudos referenciados neles, compondo nosso campo de discussão.

O ponto inicial é a compreensão do corpo como a forma material de expressão do ser no mundo, ou seja, sendo corpo percebemos, pensamos, agimos, observamos, nos

\footnotetext{
${ }^{1}$ Este artigo é parte sintetizada da Dissertação de mestrado: Dança e corporeidade: experiências e reflexões na formação continuada de professores.

Disponível na íntegra: https://repositorio.unesp.br/handle/11449/149761.

62

RELEDUC | ISE | v. 2 | n. 1 | fev. 2019
} 
comunicamos por ele. Nossas ações dão forma à existência, integram trajetórias e tecem um campo de significados expressos pela cultura.

Ao pensar o ser humano a partir de sua condição corporal se rompe a dicotomia elaborada por Descartes ${ }^{2}$ no qual a realidade é concebida somente por meio da elaboração mental (razão). A consciência é parte sim de nossas experiências, porém como aponta Barco (2012), há um sentido pré-reflexivo em nós presente na maneira de perceber e se relacionar com o mundo. Quando se vê algo, por exemplo, não se olha com a consciência, com o pensamento, mas se olha no ato de ver.

Não há visão sem pensamento. Mas não basta pensar para ver: a visão é um pensamento condicionado, nasce "por ocasião" do que acontece no corpo, é "excitada" a pensar por ele. Ela não escolhe ser ou não ser, nem pensar isso ou aquilo. Deve trazer em seu cerne aquela gravidade, aquela dependência que não lhe podem advir por uma intromissão de fora. (Merleau-Ponty, 2013 p. 36)

Assim, corpo, percepção e consciência compõem o ser humano e sua relação com outrem $^{3}$ e o mundo. Este indivíduo insere-se em um tempo histórico, dentro de uma comunidade sócio cultural, sendo assim, delineado por este contexto. As experiências e reflexões, que ocorrem ao longo de uma trajetória de vida, podem possibilitar a transcendência desta conjuntura quando se dá um processo de conscientização relacionado a compreensão de si e da realidade, sendo este um movimento de (re)construção da cultura - modos e meios de ser e criar o mundo.

Portanto, aderimos a um conceito de cultura que engloba o campo simbólico e material das atividades humanas. Sua organização ocorre com a fixação dos grupos humanos em regiões por meio do domínio de técnicas de agricultura e o desenvolvimento de capacidades de comunicação (Garaudy, 1980). Este é o marco inicial do processo civilizatório expresso na corporeidade humana na elaboração, construção e relação com a existência.

As diversas comunidades possuem diferentes concepções de vida e intencionalidades próprias, presentes na cultura, que são transmitidas no contexto social. Este processo se caracteriza no fundamento da educação: uma experiência que carrega em si uma relação essencial entre os indivíduos, a família, a sociedade, a história e o mundo (REZENDE, 1990).

\footnotetext{
${ }^{2}$ René Descartes (1596-1650), filósofo.

${ }^{3}$ Outrem é utilizado em contraposição a outro, não se referindo à alguém ou algo específico, mas sim àqueles com que nos situamos, sendo um com o outro no mundo. 
Para Freire (2015) a educação é um processo permanente que ocorre tanto dentro das experiências dialógicas com outrem e o mundo, a todo momento, como na formalidade de instituições de ensino. Sendo assim, uma experiência relacional entre quem ensina e quem aprende, compondo um campo coletivo de integração de corporeidades (intercorporeidade ${ }^{4}$ ). Ela também necessita ser significativa para os sujeitos, perpassando por temas que compõem suas experiências de vida de forma a dialogar e não impor significados. A educação deve problematizar a cultura para desvelar a realidade, proporcionando a emancipação dos indivíduos. Ao promover reflexão referente a experiência existencial pode surgir a liberdade, a autonomia e a transformação da cultura e da sociedade.

Nesta direção, a educação é humanização ${ }^{5}$ dos sujeitos, vai de encontro a construção do ser ontológico, apontado por Freire (2015) como inacabado, e que se faz a partir de suas histórias, experiências e corporeidades, processualmente produzindo saberes. Portanto, os professores que são os mediadores do processo ensino aprendizagem devem em sua formação percorrer uma trajetória significativa e reflexiva quanto à sua própria existência.

Porém, como nos aponta Schön (2000), os sistemas institucionalizados de formação de professores, iniciais e/ou continuados estão organizados ainda com base em conhecimentos racionais técnicos, formando profissionais para a resolução de problemas adequados a finalidades específicas. Este é também, o modelo usualmente praticado desde a educação básica na qual os conhecimentos do campo científico se organizam em disciplinas transmitidas por ordem de complexidade por áreas específicas. A fragmentação da educação-cultura-ciência humana, já a algumas décadas distancia-se da realidade vivida na sociedade, deflagrando segundo Schön (2000), uma crise que atinge todas as áreas profissionais.

Assim, entendemos que a formação de professores não deva distanciar-se do dinamismo da vida social na modernidade, e, as modalidades de formação continuada e contínua em serviço não podem servir somente para a atualização de conhecimentos e processos de aprendizagem. Pois, conforme pesquisas organizadas pela Fundação Victor Civita (2011), estes processos ainda mantêm sistemas de treinamento, capacitação e aperfeiçoamento de professores com

\footnotetext{
${ }^{4}$ Intercorporeidade é um termo utilizado pelo filósofo Maurice Merleau-Ponty (1903-1961) em sua obra: O visível e o invisível, para salientar que a relação entre os indivíduos se dá por um corpo sujeito, isto é, somos no mundo por nossa condição corporal.

${ }^{5}$ Humanização é um termo utilizado por Paulo Freire, em sua obra Pedagogia do Oprimido ( $1^{\circ}$ ed. 1968), para expressar o processo de conscientização dos sujeitos a partir de seu entendimento de sua condição existencialcultural. Neste sentido, Freire apresenta a relação dialógica no campo educativo como possibilidade de emancipação e, assim, humanização dos sujeitos.
} 
enfoque na transmissão passiva e instrumental de conhecimentos, seja por meio de cursos e/ou palestras de curta e longa duração em instituições de ensino e/ou no próprio local de trabalho.

Para aproximar a formação da realidade que permeia nossas vidas, autores como Ghedin (2005) empreendem trabalhos que apontam o fomento à processos reflexivos na formação continuada e contínua em serviço de professores como possibilidade de percepção da realidade a partir da visão dos próprios sujeitos. Para o autor, o professor inicia este processo enraizado no senso comum e ao longo do tempo chega à elaboração de um pensamento crítico no qual ele(a) passa a inquietar-se com a sua própria prática e reconstruir sua realidade. Sendo assim, o(a) professor(a) se percebe como um sujeito que produz e não transfere conhecimento (FREIRE, 2015).

Ao falar da formação da pessoa do professor, vejo um espaço onde o mesmo pode atuar e decidir sobre algumas estratégias de ação, pois acredito que num determinado momento da história individual seja possível tomá-la nas mãos e modificá-la, resistindo com firmeza e rigor aos percalços, desde aqueles que nos aparecem pelas contingências da situação, até aqueles devidos à nossa resistência à mudança e à aceitação do novo. (OLIVEIRA DE JESUS, 2000, p.110)

É assim, que Tardif (2010) organiza a relação do saber dos professores com a pessoa, a identidade, a experiência de vida, a história profissional, as relações com os alunos e os outros atores escolares. Incluindo o ser e o agir dialeticamente integrados ao transitarem pelo campo da emoção, reflexão, expectativas e engajamentos, articulados aos conhecimentos científicos produzidos na universidade.

Ora, um professor de profissão não é somente alguém que aplica conhecimentos produzidos por outros, não é somente um agente determinado por mecanismos sociais: é um ator no sentido forte do termo, isto é, um sujeito que assume sua prática a partir dos significados que ele mesmo lhe dá, um sujeito que possui conhecimentos e um saber fazer provenientes de sua própria atividade e a partir dos quais ele a estrutura e orienta. (TARDIF, 2010, p.230).

Estes conhecimentos estão emaranhados as corporeidades e compõem a ciência, a cultura, os saberes populares e acreditamos serem fundamentais na educação como veículo de emancipação. Nesta direção, apresentamos a dança, uma prática cultural simbólica, apontada por Garaudy (1980) como uma linguagem que integra o ser, a natureza, a cultura e a sociedade. Os movimentos corporais ritmados compõem a corporeidade de grupos sociais e integram a 
educação, veiculando uma constelação de sentidos que guardam a história da construção da vida humana.

Nesta perspectiva, no início do século XXI, Silva (2013) aponta a necessidade de pesquisadores da área da dança no Brasil compreenderem o processo de escolarização e o fazer artístico pertencentes a esta área. $\mathrm{O}$ entrelaçamento de conceitos, propostos neste artigo, adere a este contexto e objetiva apontar por meio de trajetórias de vida dançantes as experiências e reflexões de professores que viveram o gesto em um processo de percepção de si, outrem e do mundo.

Pôr e se pôr em movimento no momento, tornar-se imperceptível, a gente se torna todo mundo, e o mundo se torna, incessantemente, outro e a gente. Longe de um realismo homogêneo e asséptico, esse andar comum deixa ver aquilo que na dança tece a sensação variável com a efetuação do passo, feita imagem sem necessariamente imitar, em uma partilha entre aquilo que é sentido, aquilo que é feito e aquilo que é visto. (BARDET, 2014, p. 104)

Contudo, observamos dificuldades referente a ideia de relevância da contribuição desta linguagem na formação humana, pois são os conhecimentos racionais técnicos veiculados por conceitos abstratos que compõem a maioria das disciplinas educacionais. A sensibilidade pautada em uma educação estética sintonizada a nossa condição corporal quando ocorre se condiciona a superficialidade de uma cultura massificada e homogeneizante, cujo corpo é visto como objeto e a dança como performance ${ }^{6}$.

Na formação de professores, de maneira geral, a dança está presente como conteúdo específico da cultura corporal de movimento ${ }^{7}$ e da educação estética ${ }^{8}$. Os saberes e reflexões deste campo, correntemente se organizam no refinamento do gesto motor e na vivência de diferentes estilos de dança. Porém, acreditamos que o professor deve conhecer o que está implícito aos gestos dançantes, isto é, a história, a diversidade e os saberes que compõem a

\footnotetext{
${ }^{6}$ No contexto deste artigo, performance significa a execução de gestos motores. Este termo possui um outro sentido relacionado a um espetáculo no qual o artista atua com inteira liberdade, interpretando papéis ou criações de sua própria autoria.

${ }^{7}$ A cultura corporal de movimento é utilizada pelo "Coletivo de autores" (Castellani Filho, L. et al, 1992) para denominar o campo de atuação e a metodologia do ensino de Educação Física.

${ }^{8}$ A Educação Estética se dá muito antes do professor entrar na universidade, de ser estudante de qualquer área do conhecimento. A bagagem estética que traz, que utilizará em todos os contatos com a expressão humana começa quando nascemos em um desenvolvimento que vem de todos os sons que escutamos, das visões que temos. In: BARBIERI, Stela. Interações: onde está a arte na infância. São Paulo: Blucher, 2012, P. 143-158.
}

66

RELEDUC | ISE | v. 2 | n. 1 | fev. 2019 
expressão corporal, podendo ir além, ao promover a reflexão a partir do movimento. Sendo assim, um agente mediador de um processo educativo em sintonia com a vida das pessoas.

No termo "mediar" está implícita a ideia de "estar entre". Nem à frente, nem por trás - no meio. Como articulações, que permitem dobrar, estender, afastar, aproximar, flexibilizar, enrijecer, alavancar, impulsionar, num movimento incessante de pequenos ajustes para manter o equilíbrio e o sangue circulando. Atuar como mediadores envolvidos, mas com um olhar atento a cada movimento, a cada dúvida, a cada novo desejo, transitando entre o dentro e o fora, orientando à medida que vão se revelando novas conquistas e dificuldades, indicando direções, facilitando, alavancando, provocando, impulsionando, estimulando a construção de um pensamento/espírito crítico, onde as pessoas se tornarão sujeitos de suas danças. (WERNECK, 2008, p.108-109, grifo nosso)

Neste ponto, é importante perceber que quando reproduzimos uma dança, acessamos sentidos expressos nos movimentos. Muitas vezes, esta simbologia veicula aspectos de uma cultura hegemônica, presente em um sistema de classes, no qual Chauí (1986) aponta uma sobreposição de valores que visam homogeneizar e massificar a corporeidade dos indivíduos, padronizando e estereotipando comportamentos. Portanto, é necessário perceber que o dançar não é neutro, revela uma ideologia presente em um dado contexto histórico social. Na tomada de consciência desta inserção no mundo é que a criação de novas danças pode alavancar, impulsionar, transformar e movimentar os meios-modos de ser. Esta é a justificativa em adentrar as trajetórias de vida de professores que vivem a dança e com ela se (re)elaboram em travessias.

Travessia pelo quê? Por nada, talvez, ou por uma energia, ou por uma graça porém, qualquer que seja a palavra, travessia do corpo pelo incorporal que o retira da organização e da sua finalidade de corpo. O corpo se torna o incorporal de um sentido que, no entanto, não está em outra parte que não através do corpo. Um sentido em travessia mais do que um sentido da travessia (...). (BARDET, 2014, p. 62 - nota de rodapé).

\section{DESENVOLVIMENTO}

Consideramos ser uma oportunidade e também um desafio buscar compreender a elaboração da corporeidade de professores de dança e elegemos em nosso auxílio, na perspectiva das Ciências Humanas, a abordagem qualitativa para organizar metodologicamente 
este estudo. Utilizamos os trabalhos em pesquisa qualitativa de Lüdke e André (1986); e Martins e Bicudo (1994) para alcançar o olhar dos sujeitos referente ao fenômeno aqui estudado, pois eles se alinham à descrição de trajetórias de vida dos sujeitos que ao rememorarem, revisitarem, reelaborarem e organizarem no presente experiências anteriores, vão compondo um quadro existencial repleto de sentidos. "Assim, o apelo às recordações pressupõe aquilo que ele deveria explicar: a colocação em forma de dados, a imposição de um sentido ao caos sensível" (MERLEAU-PONTY, 2014, p.44).

Para a análise destas descrições, utilizamos como inspiração os estudos de Freire (2015) relacionados à investigação de temas geradores, na educação, que tomam a direção de experiências relevantes na vida das pessoas. Este trabalho nos fez compreender que o pensamento reflexivo revela uma práxis de vida que vai se dando em períodos e produz observações entre partes da trajetória dos sujeitos à um todo. Ocorrem também, abstrações que proporcionam o entendimento de um movimento dialético entre o pensar, o sentir e o agir que apontam como estas pessoas compreendem suas inserções no mundo. E, não perdemos de vista a elaboração teórica, que traçamos na introdução deste artigo, com o entrelaçamento dos conceitos de corporeidade, cultura, dança e formação de professores.

O contato com os professores, que participam deste estudo, se deu ao longo de um Curso de aperfeiçoamento em dança, oferecido como formação contínua em serviço e realizado por uma Prefeitura Municipal de cidade do interior do Estado de São Paulo. Elegemos para a escolha destes colaboradores três critérios: serem professores de dança desta Prefeitura9 atuarem com públicos diversos (crianças, jovens, adultos e terceira-idade) e terem participado durante todo o processo de formação desenvolvida pela gestão pública, com duração entre os anos de 2006 e 2011. Seis professores se encaixaram neste perfil, quatro deles concordaram em participar da pesquisa, sendo três mulheres e um homem com média de idade de cinquenta e três anos. Três deles possuem formação profissional em Educação Física, na década de oitenta, tendo contato com a dança também, na educação informal, e um deles tem formação em Artes Plásticas.

Organizamos a coleta de dados por meio de entrevista semi-estruturada disposta em três blocos de significação. Na análise, utilizamos os mesmos blocos e intersecções entre eles para chegarmos às nossas considerações finais.

\footnotetext{
${ }^{9}$ Durante um período do Curso, houve a participação de professores de dança de Academias e outros projetos da cidade.

68

RELEDUC | ISE | v. 2 | n. 1 | fev. 2019
} 
Apresentamos o primeiro bloco com questões que permeiam a dança e suas relações com a percepção de mundo, visando um mergulho nos significados mais gerais ao longo de trajetórias de vida. Verificamos, nas narrativas, tanto pontos semelhantes quanto singularidades dançantes em contextos pessoais e profissionais. Assim, observamos que três professoras tiveram contato com a dança na infância, em contexto familiar, e durante as formações básica e profissional. Apontaram percepções em relação ao seu próprio movimento e dos seus grupos de inserção, descreveram suas práticas pedagógicas e suas relações com seus alunos. O conceito de dança se alinhou a repetição puramente dos gestos e também ao prazer em movimentar-se. O professor teve contato com a dança na idade adulta pela linguagem cinematográfica, apresentando uma experiência que considera arrebatadora pela eclosão de um sexto sentido: a cinestesia $^{10}$.

Em relação as particularidades, uma professora revela a valorização da dança dentro de uma cultura elitizada, mas demonstra a compreensão das ideologias e valores intrínsecos a esta visão. Outra enfoca a dança por meio da descrição de afetos familiares vividos na infância. Aponta também, sua diferenciação de percepção entre modalidades de dança como o ballet clássico e o jazz que respectivamente se relacionam a contenção e liberdade do corpo em movimento. Finalizando com a reflexão acerca de suas práticas docentes, que segundo ela, ampliam suas relações consigo mesma, com o movimento, com seus alunos e a faz buscar uma vida mais plena.

A terceira professora atribui, sua vivência com a dança, a passagem de algo desconhecido para a aceitação e valorização de si e do outro, elaborando saberes que vão sendo compartilhados em sua vida pessoal e vislumbrando a possibilidade de outras pessoas realizarem esse percurso: “(...) porque eu acho importante o movimento. Porque eu me sinto tão bem fazendo qualquer atividade física, qualquer movimento, que eu quero que todo mundo faça”.

Para o professor a dança se entrelaça a sua vida e desperta uma estética que gera descobertas, buscas, transformações, ações, novas experiências e reflexões. Estes elementos abrem caminhos para ele invistir em sua formação, visando apreender e transmitir o que ele

10 Cinestesia - sensação interna dos movimentos do próprio corpo, pode ocorrer quando estamos nos movimentando, ou então quando observamos o movimento de outros. SUQUET, Annie. Cenas. O corpo dançante: um laboratório de percepção. In: COURTINE, Jean-Jacques; VIGARELLO, Georges (org.). História do corpo. 3. As mutações do olhar. O século XX. Petrópolis, RJ: Vozes, 2008, p. 509-540. 
próprio sente em relação ao dançar. Portanto, revela uma transformação em si que se expressa por sua intenção de ser mais parceiro e solidário com as pessoas.

No segundo bloco, focamos na experiência e nos significados da dança vividos na formação inicial e continuada. Neste sentido, o dançar esteve presente na prática da ginástica aeróbica, objetivando o alcance de um modelo ideal de estética corporal presente também na experiência que tiverem como alunos de dança na educação informal. No período de formação continuada as experiências distintas e não sistematizadas aparecem nos relatos pelo contato com técnicas de dança, sendo que a questão propriamente do ensino não esteve presente de maneira reflexiva e sistematizada.

Particularmente, no relato de uma das professoras foi possível observar uma elaboração ligada a questões sócio culturais e um engajamento pessoal. Durante, a formação continuada, aspectos políticos e ideológicos presentes na cultura de massa foram vivenciados sem problematização e criticidade. Apesar disso, aponta características da corporeidade dos professores com quem teve contato em suas formações.

Para outra professora, a formação não formal em dança foi seu alicerce na construção de práticas como docente. Neste sentido, suas reflexões são expressas na contradição de suas palavras "foi tudo de bom”, mas hoje não faria dessa maneira.

A terceira professora revela reflexões dentro de suas práticas docentes com a dança e a ginástica, no sentido da superficialidade do ensino pautado na simples cópia de gestos, pois compreende que a dança é muito mais que o movimento corporal. Aponta que a possibilidade de criar seus próprios movimentos proporcionou uma compreensão de si mesma e de seus alunos.

Neste bloco, o professor nos leva a perceber a importância do contato com colegas de trabalho e a curiosidade como elementos que nos enriquecem globalmente, pois trazem uma percepção de que a cada nova experiência dançante surgem sentimentos que não cessam, mas que o levam a conectar-se com sua essência.

Porque o diálogo travado com essas pessoas e mesmo o meu olhar, quando eu passei a assistir outros filmes, outros documentários relacionados a dança. Não é aquele corpo que se apresenta, que ficou (...) quer dizer ele nem ficou ali, ele passou. A gente viu, mas não tem mais como voltar. Você pode fotografar, ou filmar, não está ali mais, não é contínuo desta forma. A não ser dentro (...) dentro de mim. Dentro da minha alma, dentro do meu sentimento. 
No terceiro bloco fomos ao encontro específico da participação destes professores no Curso de aperfeiçoamento em dança, oferecido na modalidde de formação contínua em serviço. Consideramos importante esclarecer que a proposta deste Curso esteve em sintonia com um projeto de Educação popular e democrática, não somente a nível escolar. Neste sentido, o município que ofertou o Curso, já proporcionava uma série de ações na educação não formal, visando ampliar o olhar para a formação humana nos diferentes espaços sociais. Os Centros de Cultura e Centros Comunitários, dentre outros espaços, ofereciam uma série de atividades artísticas, esportivas, artesanais e de interação entre as pessoas da comunidade local. A gestão buscou, nos educadores dessas instituições, uma articulação para que as ações fossem implementadas, porém percebeu uma dissonância entre sua proposta e as práticas dos professores de dança. Assim, o Curso direcionou um olhar para a organização do gestual humano voltado para o diálogo cultural, visando um desenvolvimento do ser e das comunidades nas quais os professores estavam inseridos. Havia uma clareza de que as práticas desses professores tinham como ponto determinante suas trajetórias formativas. Como a maior parte dos professores é formada em Educação Física, na década de oitenta, o modelo preponderante dessa formação, segundo Gonçalves Júnior (2003), era o esportivista. Sendo assim, a base do ensino estava atrelada à aquisição de habilidades motoras para a realização dos gestos. A dança era tratada na mesma lógica e se organizava dentro de atividades da ginástica rítmica, aeróbica e olímpica. Alguns desses professores possuíam também experiências com a dança na educação não formal, em academias, nas quais o ensino seguia também o modelo esportivista, ou seja, reprodução e aperfeiçoamento do gesto motor. A proposta do Curso não era negar as experiências desses professores em seus contextos de formação e de vida, mas proporcionar novas experiências e reflexões em suas práticas docentes no campo teórico e prático do ensino, na criação de danças que possibilitassem um diálogo com a cultura das comunidades locais. Como cita Marques:

Professores são responsáveis pelas escolhas metodológicas que abrirão caminhos nos entrelaçamentos das relações entre o conhecimento específico da dança e seus alunos, entre a arte e o ensino. Enfim, entre o conhecimento, os alunos, a arte e a sociedade. (2010, p.16)

Consideramos que a metodologia de ensino do Curso era o ponto estratégico para proporcionar vivências com a experimentação e criação de movimentos embasados nos estudos 
de Rudolf Laban ${ }^{11}$. A bibliografia também esteve em sintonia com as atividades práticas e o estudo teórico dos campos de ensino e criação artística. Buscou-se a estratégia de trabalhar com rodas de conversa no início e final dos encontros para dialogar com as percepções e reflexões dos professores. As práticas docentes, também foram acompanhadas ao longo do desenvolvimento desta formação. Enfim, houve a preocupação na articulação entre o ensino, a concepção de dança e o escopo de atividades desenvolvidas pelos professores, tais como: organização, coordenação e direção de apresentações artísticas, pensando no constante diálogo entre docentes, alunos, comunidade e cultura.

O que se expressa de maneira geral no relato dos professores, neste período, foram sentimentos de medo, desespero, dúvidas, angústias, choque, resistência e questionamentos entre o certo e o errado em relação ao dançar. Estamos em contato com vidas dedicadas à dança, ligadas a um dado status profissional que revela campos de atuação de saberes, de condicionamentos que perpassam as esferas da existência. Os questionamentos explicitamente presentes na narrativa do professor compõem implicitamente os demais relatos e são considerados por nós como fundamentais para que o Curso pudesse transformar não somente as práticas destes professores, até porque não acreditamos na transformação de ações sem a transformação das pessoas. Ao tomarmos a direção de uma educação emancipadora, o fato de ocorrerem questionamentos já demonstra a capacidade destes professores em refletirem criticamente. Este é o ponto principal considerado na análise do quarto bloco, bem como, as especificidades vividas no momento da formação contínua em serviço.

Para uma das professoras, neste período, houve a passagem de um olhar construído na formação inicial e continuada para um novo olhar que consideramos gerar uma abertura. É fundamental, apontarmos que isso só foi possível pela curiosidade e busca de conhecimento desta professora, aspectos que consideramos ser parte de como ela atua no mundo, ou seja, sua corporeidade.

\footnotetext{
11 Rudolf Laban (1897-1958) nasceu na atual Bratislava e foi dançarino, coreógrafo, teatrólogo, musicólogo, considerado como o maior teórico da dança do século XX e como o "pai da dança-teatro". Dedicou sua vida ao estudo e sistematização da linguagem do movimento em seus diversos aspectos: criação, notação, apreciação e educação. Desenvolveu uma metodologia de análise do movimento a partir do estudo dos "esforços". Esta abordagem possibilitou uma melhor compreensão da movimentação humana geral. Em seu trabalho criativo e de análise da dança, Laban se dedicou à realização de propostas de dança para as massas, desenvolvendo com esta finalidade a arte da Dança Coral, onde grande número de pessoas se move juntas, segundo uma coreografia de estrutura simples, porém instigante, que permita bailarinos e pessoas leigas dançarem juntas de forma colaborativa. https://pt.wikipedia.org/wiki/Rudolf_Laban Acesso: 25/11/2015
} 
Outra professora acredita que o Curso trouxe potenciais de transformação, clareando suas ideias. Ela cita os processos criativos em dança como um encontro com a liberdade, o diálogo para a discussão de caminhos na prática e na docência como significativos, levando-a refletir sob um novo olhar a dança. Aponta que neste processo, não foi necessário abandonar sua história, mas sim compreender que todo dia é possível melhorar e agregar mais pessoas as práticas da dança.

No relato da terceira professora ocorreu um processo de superação ligado a transposição de algumas fronteiras que a fez se valorizar e valorizar o outro. Isto demonstra que diferentes experiências no contexto do Curso levaram-na a perceber sua resistência e medo em se expor, aspectos não diretamente relacionadas aos conhecimentos veiculados neste período, mas expressos em suas práticas pedagógicas como um todo como ela mesmo relata.

Para o professor é relevante o aspecto de convivência durante o Curso, o que segundo ele, possibilita confiar e sentir uma permissão para se entregar as propostas. Neste percurso, apreende um conceito de dança que colabora com a organização e transformação de suas práticas construídas a partir de suas experiências e reflexões.

\section{CONSIDERAÇÕES FINAIS}

Com a análise dos relatos, nos aproximamos da compreensão da elaboração da corporeidade de professores de dança, no contato com suas experiências e reflexões ao longo de suas trajetórias de vida pessoal e profissional. A corporeidade revelou-se como o próprio caminho existencial a qual se somam experiências relacionais em meio à contextos históricos e culturais. A nossa vida congrega aspectos biológicos, psicológicos, antropológicos em uma trama no qual o corpo é sujeito, apreende o mundo, gera sentidos e organiza a consciência. Isto deflagra um processo reflexivo gerado na recordação de experiências vividas que fazem surgir nos relatos destes professores as palavras e expressões: "fazer bem,felicidade, compartilhar, mudar a minha vida, eu acho que eu já nasci com esta vontade de dançar”. A dança se mostra como espaço de integração do ser no mundo, possibilitando o entrelaçamento da sensibilidade e da racionalidade ao revelar que o movimento traz um sentido de unidade do ser que pensa, (re)elabora, transcende, retoma e transforma. Assim, como aponta uma das professoras, " $a$ dança é o impulso da alma”. 
Os aspectos apresentados aqui e sua análise compõem as trajetórias singulares destes professores de dança, perpassam suas formações profissionais, integram suas corporeidades e conclamam nosso engajamento por uma educação que não negue os sentimentos e o movimento como fonte de construção de conhecimento de si e de apreensão da realidade.

A dança como uma manifestação cultural da diversidade dos povos, como fonte de saberes e de problematização da existência subjetiva e coletiva, uma prática dialógica com abertura para a elaboração de novos caminhos.

Talvez, justamente na contradição e na tensão instauradas entre a disciplina da ordem dos corpos que dançam e dos projetos que renovam, geração após geração, o desejo de desmontar essas barreiras que constituem a dança em seu ensino, sua prática e sua arte. Então, se ela é habitualmente devolvida a essa geração, a desierarquização não pode ser tomada como uma etapa histórica transposta pela primeira vez e de uma vez por todas, mas como a tendência incessantemente reposta em jogo desse desejo de emancipação das ordens preestabelecidas daquilo que constitui a dança em seus paradoxos estéticos. O ato, não aquele da declaração histórica dessa desierarquização por meio de uma repartição dos pesos, mas aquele sempre renovado da experiência girante dos jogos de forças em curso e dos lugares da dança. A inconclusão intrínseca a esse gesto, própria de seus trâmites, de seus conflitos e de suas contradições, constitui menos a fronteira intransponível para um mundo ideal, jamais atingindo, a partir do qual julgar os fracassos de todas as tentativas e fixar o programa das próximas etapas de seu progresso, mas os limites a serem incessantemente percorridos e deslocados do ato estético. (Bardet, 2014, p.112-113)

\section{REFERÊNCIAS}

BARBIERI, S. Interações: onde está a arte na infância. Tradução: Regina Schöper, Mauro Baladi. São Paulo: Blucher, 2012.

BARCO, A. P. A concepção Husserliana de corporeidade: a distinção fenomenológica entre corpo próprio e corpos inanimados. Synesis, Petrópolis, v.4, n.2, p. 1-12, ago/dez. 2012.

BARDET, M. A filosofia da dança: um encontro entre dança e filosofia. São Paulo: Martins Fontes - selo Martins, 2014.

BRASIL. Fundação Carlos Chagas. Formação continuada de professores: uma análise das modalidades e das práticas e Estados e Municípios Brasileiros. São Paulo: Fundação Victor Civitta, 2011.

CASTELlani FILHO, L. et al. Metodologia do ensino de Educação Física. São Paulo: Cortez, 2009. 
CHAUÍ, M. Conformismo e resistência. Aspectos da cultura popular no Brasil. $6^{\circ}$ reimpressão. São Paulo: Editora Brasiliense S/A, 1996.

FREIRE, P. Pedagogia do oprimido. 59 ed. Rio de Janeiro: Paz \&Terra, 2015.

Pedagogia da Autonomia. Saberes necessários à prática educativa. $51^{\circ}$ ed. Rio de Janeiro: Paz \& Terra, 2015.

Conscientização. São Paulo; Cortez, 2016.

GARAUDY, R. Dançar a vida. Rio de Janeiro: Nova Fronteira, 1980.

GHEDIN, E. A reflexão sobre a prática cotidiana - caminho para a formação contínua e para o fortalecimento da escola enquanto espaço coletivo. In: BRASIL. Ministério da Educação. Formação de professores. Boletim 13, agosto 2005, p. 24-32.

GONÇALVES JUNIOR, L. Cultura corporal: alguns subsídios para sua compreensão na contemporaneidade. São Carlos - EDUFSCar, 2003.

LÜDKE, M.; ANDRÉ, M.E.D.A. Pesquisa em Educação: Abordagens qualitativas. São Paulo: EPU, 1986

MARQUES, I. Linguagem da dança. Arte e ensino. $1^{\circ}$ ed. São Paulo: Digitexto, 2010.

MARTINS, J.; BICUDO, M. Ap. V. A pesquisa qualitativa em psicologia. Fundamentos e Recursos básicos. 2 ed. São Paulo: Editora Moraes, 1994.

MERLEAU - PONTY, M. Fenomenologia da percepção. $4^{\circ}$ ed. São Paulo: Martins Fontes, 2014.

O olho e o espírito. $1^{\circ}$ ed, Cosac Naif Portátil. São Paulo: Cosac Naif, 2013.

OLIVEIRA DE JESUS, L. de F. Autoformação: conhecendo a vida e o trabalho de professoras e professores. In: BUENO, Belmira Oliveira; CATANI, Denise Bárbara; SOUZA, Cynthia Pereira de (orgs.). A vida e o ofício dos professores. $2^{\circ}$ ed. São Paulo: Escrituras Editora, 2000, p. 101-110.

REZENDE, A. M. de. Concepção Fenomenológica da Educação. São Paulo: Cortez, 1990.

SCHÖN, D. A. Educando o professional reflexivo: um novo design para o ensino e a aprendizagem. Porto Alegre: Artmed, 2000.

SILVA, C. F. da. Por uma história da dança: Reflexões sobre as práticas historiográficas para a Dança, no Brasil contemporâneo. 2012, 121 f. Dissertação (Mestrado) - Escola de Dança, Universidade Federal da Bahia, Salvador, Salvador. 2013.

TARDIF, M. Saberes docentes e formação profissional. Petrópolis, RJ: Vozes, 2010.

$$
\text { RELEDUC | ISE | v. } 2 \text { | n. } 1 \text { | fev. } 2019
$$

